\title{
Microstructure of biopolymer-modified aerial lime mortars
}

\author{
Tomáš Žižlavský ${ }^{1, *}$, Martin Vyšvařil ${ }^{1}$, Patrik Bayer ${ }^{1}$, and Pavla Rovnaníková $^{1}$ \\ ${ }^{1}$ Brno University of Technology Faculty of Civil Engineering, Veveří 331/95, 60200 Brno, Czech \\ Republic
}

\begin{abstract}
Cellulose-based viscosity-modifying admixtures are used on daily basis in a wide range of building materials, dominantly in pre-mixed mortar systems. Lately, alternative admixtures such as different "gums" have emerged. In building materials, the gums have similar viscosityenhancing effects as cellulose ethers with different efficiency. Various ways of production, as well as diverse working mechanisms of the biopolymers are to be considered while choosing the most suitable admixture for the intended use. Influence of alternative admixtures in several doses on the microstructure of lime mortars was studied in this paper. Mortars were prepared with the same workability and the air content in fresh mortar was determined, for it can have notable impact on microstructure of hardened mortar. Hydroxypropyl derivative of chitosan showed air entraining ability, while the carboxymethyl derivative reported slight decrease in amount of air entrained into the mixture. In the case of diutan gum, the most water-demanding admixture, the percentage of entrained air dropped with growing dose. Admixture addition increased the volume of pores in diameter lower than $0.1 \mu \mathrm{m}$, and in region of pores around $10 \mu \mathrm{m}$. Only the diutan gum affected the distribution of capillary pores, which are typical for lime mortars. Hygric properties were in correlation with air content values.
\end{abstract}

\section{Introduction}

The aerial-lime as a binder has been used thorough the centuries for the whole complex building system from the filling concrete in the hollow masonry up to the fine decorative plastering. Poor durability is the main disadvantage of lime-based materials, especially while used in exterior conditions, where it requires continuous maintenance. Where the upkeep is omitted or the complexity of the system is disrupted by the incompatible materials the inevitable damage to the building occurs causing irreversible loss of architectural and cultural heritage. The durability of the material is determined by a large amount of factors starting from the application and curing conditions up to the microstructure of the final product.

According to A. Izaguirre et al [1], the durability and mechanical properties of lime mortars are closely linked with water absorption capacity, which is mostly affected by

* Corresponding author: zizlavsky.t@fce.vutbr.cz 
the porosity of the material. The porosity is affected by several different influences, mainly the amount of kneading water, and the chemical and mineralogical composition of the aggregate. It is generally acknowledged that the calcareous aggregate (mostly limestone) produces mortars with slightly better parameters in comparison with silicate aggregate [2-6]. However the theories to explain the mechanisms behind are various and even the effects on the porosity of mortars are significantly different in studies with seemingly similar parameters $[2,6]$. The total porosity and the main pore diameter increase in the lime paste with growing water content [7] however, the physico-mechanical properties of aerial lime are reported to be unaffected by the higher porosity, thus being non-compliant with the Power equation generally accepted in the world of hydraulic binders. Even though, the amount of kneading water is still the factor affecting the strength [8] of the lime mortar, but with lower sensibility in the range of usual values in comparison with hydraulic binders [9].

The use of water-retentive admixtures, usually with viscosity-modifying function, is widely spread in building materials industry, mainly in the ready-mix products and selfconsolidating concrete $[10,11]$. These, mostly cellulose-based, admixtures ensure that the sufficient amount of water remains in the mixture thorough the curing time, and the water is not unduly blotted by the support material or the environmental conditions such as sun or wind. Apart from cellulose-based materials, the admixtures based on biopolymers from other natural sources are being studied and used [10]. These alternative biopolymeric admixtures were found more suitable for aerial-lime based materials than the cellulose ethers $[1,12,13]$.

The study focuses on direct comparison of effects of the four alternative biopolymeric admixtures, hydroxypropyl and carboxymethyl derivatives of chitosan ( $\mathrm{HPCH}$ and $\mathrm{CMCH}$ respectively) as representatives of artificially modified substances, diutan gum (DG) representing biopolymers of microbial origin, and sodium salt of alginic acid (ALGNA) obtained from seaweed, similarly to agar or carrageenan, on the microstructure of aerial lime-based mortars. The use of most of the admixtures in lime mortars was studied mainly by the authors using constant water/binder ratio which unfavourably affected the results by highly altered workability, especially in higher doses of more efficient admixtures $[14,15]$. This study aims to exclusion of this undesirable effect by preparing all the mortars with the same consistency according to European standards. This approach is also closer to the practical application of mortars, where the workers are used to materials with similar behaviour regardless of their composition.

\section{Materials and methods}

\subsection{Materials and sample preparation}

The mortars were prepared by introducing the dry mixture composing of lime hydrate of CL $90 \mathrm{~S}$ class according EN 459-1 (Carmeuse Czech republic), siliceous sand of 0-4 $\mathrm{mm}$ fraction, and biopolymeric admixture (Table1) in the dose of $0.1 \%, 0.5 \%$, and $1 \%$ of binder weight into the specified amount of water (Table 1) to ensure the workability of $160 \pm 5 \mathrm{~mm}$ determined by the flow table test according to EN 1015-3. The mixtures were cast into prismatic moulds $40 \times 40 \times 160 \mathrm{~mm}$ and demoulded after 72 hours. The samples were cured under laboratory conditions $\left(20{ }^{\circ} \mathrm{C}, 55 \% \mathrm{RH}\right)$ until the tests, which were performed in the age of 90 days. 
Table 1. Admixtures, water/binder ratio, and air content in fresh mortar of prepared samples

\begin{tabular}{|c|c|c|c|c|c|}
\hline Abbrev. & $\begin{array}{l}\text { Chemical } \\
\text { composition }\end{array}$ & $\begin{array}{c}\text { Dosage } \\
{[\%]}\end{array}$ & $\begin{array}{l}\text { Water/Binder } \\
\text { ratio }[-]\end{array}$ & Manufacturer & $\begin{array}{c}\text { air content } \\
{[\%]}\end{array}$ \\
\hline REF & - & - & 1.025 & - & 3.90 \\
\hline \multirow{3}{*}{$\mathrm{HPCH}$} & \multirow{3}{*}{$\begin{array}{c}\text { hydroxypropyl } \\
\text { chitosan }\end{array}$} & 0.1 & 1.000 & \multirow{3}{*}{$\begin{array}{c}\text { Kraeber \& Co } \\
\text { GmbH }\end{array}$} & 3.70 \\
\hline & & 0.5 & 1.100 & & 10.00 \\
\hline & & 1.0 & 1.120 & & 11.15 \\
\hline \multirow{3}{*}{$\mathrm{CMCH}$} & \multirow{3}{*}{$\begin{array}{c}\text { carboxymethyl } \\
\text { chitosan }\end{array}$} & 0.1 & 1.030 & \multirow{3}{*}{$\begin{array}{c}\text { Kraeber \& Co } \\
\text { GmbH }\end{array}$} & 3.20 \\
\hline & & 0.5 & 1.100 & & 2.35 \\
\hline & & 1.0 & 1.180 & & 2.30 \\
\hline \multirow{3}{*}{ DG } & \multirow{3}{*}{ diutan gum } & 0.1 & 1.250 & \multirow{3}{*}{ CP Kelco } & 2.55 \\
\hline & & 0.5 & 1.475 & & 1.80 \\
\hline & & 1.0 & 1.735 & & 2.20 \\
\hline \multirow{3}{*}{ ALGNA } & \multirow{3}{*}{ sodium alginate } & 0.1 & 1.130 & \multirow{3}{*}{$\begin{array}{l}\text { Sigma- } \\
\text { Aldrich, Co }\end{array}$} & 3.30 \\
\hline & & 0.5 & 1.150 & & 4.00 \\
\hline & & 1.0 & 1.170 & & 4.30 \\
\hline
\end{tabular}

\subsection{Methods}

The porosity of the samples was determined by mercury intrusion porosimetry using Micrometrics Pore sizer 9310. From the data gathered, the total porosity of specimens and pore size distribution were obtained. The hygric properties of the prepared mortars were specified by water absorption coefficient due to a capillarity action according to EN 101518. Chosen specimens were subjected to scanning electron microscopy (SEM).

\section{Results and discussion}

\subsection{Pore size distribution}

The porosity of specimens is visualised as cumulative pore volume curves (full lines) and differential pore volume (pore volume density) (dotted/dashed lines) in the Fig. 1 and Fig. 2 with cut-outs focusing on the range of large pores from 1 to $100 \mu \mathrm{m}$ (due to a better visibility the differential pore volume has inverted y-axis in the cut-out). The shape of the cumulative curves is typical for the lime-based materials [6, 14] with the main volume of pores situated in the range between 0.1 and $1 \mu \mathrm{m}[1,3,6-8,12,14-15]$. In this interval the shape of the curve remains similar for the chitosan ethers as well as two lower doses of sodium alginate, seemingly so biopolymer addition compensates the influence of the higher water content [7], while in the case of diutan gum, the growing dosage (and water content) leads to the flatter curve, thus wider interval of the typical pore sizes. The onset of the DG curves moves significantly to the area of larger diameter pores, as observed by M. Arandigoyen et al. [7] for the mortars with growing water content, whereas the transition is not as significant as would be expected based on these results, indicating that even in this case the biopolymer addition has positive impact in the way of compensating much higher water/lime ratio. Generally, the addition of biopolymer slightly reduces the volume of pores in this area, ALGNA and $\mathrm{CMCH}$ with linear dosage dependency (the higher the dosage the higher the pore volume reduction), whereas HPCH and DG showed highest reduction in the dosage of $0.5 \%$. This is contrary to the results observed by A. Izaguirre et al. [12] on the lime mortars with guar gum addition, where the interval became narrower and the volume was slightly promoted. The effect of $\mathrm{CMCH}$ 
addition observed by M. Lasheras-Zubiate [16] on cementitious material is not present in the case of lime-based mortars.

Second largest volume increment is in the area of large pores of diameter around $10 \mu \mathrm{m}$. These pores are formed during the mixing period and are indicating the different rheology of mortars despite the similar workability defined by flow table test. The most significant difference in behaviour is between ALGNA, DG and chitosan derivatives where the air entraining function of HPCH (Table 1) [15] leads to notable increase in the volume of these pores without affecting their size distribution and other chitosan derivatives slightly reduce the amount of large pores. The ALGNA and DG have no proven air entraining function in lime mortars [17], thus the increase in volume is caused only by different behaviour of mortar during mixing. By these means, ALGNA in the highest dosage and DG in the $0.5 \%$ dose not only promote the volume of large pores, but also support the evolution of pores with larger diameter.

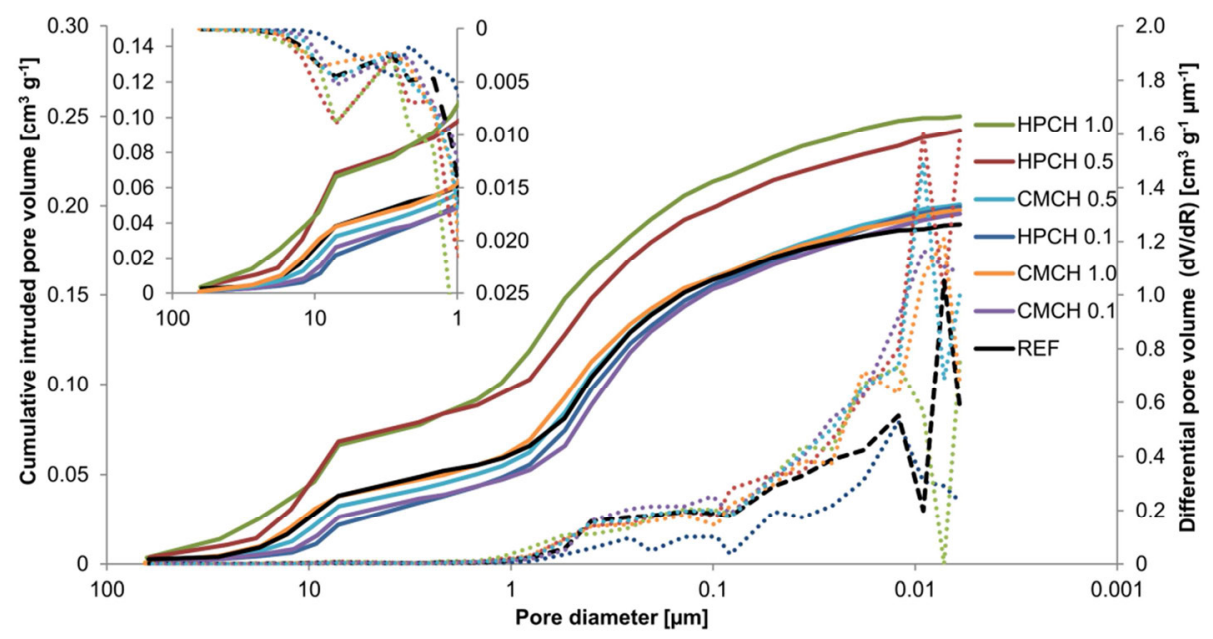

Fig. 1. Cumulative intruded pore volume and pore size distribution (dotted/dashed lines) of samples with chitosan derivatives.

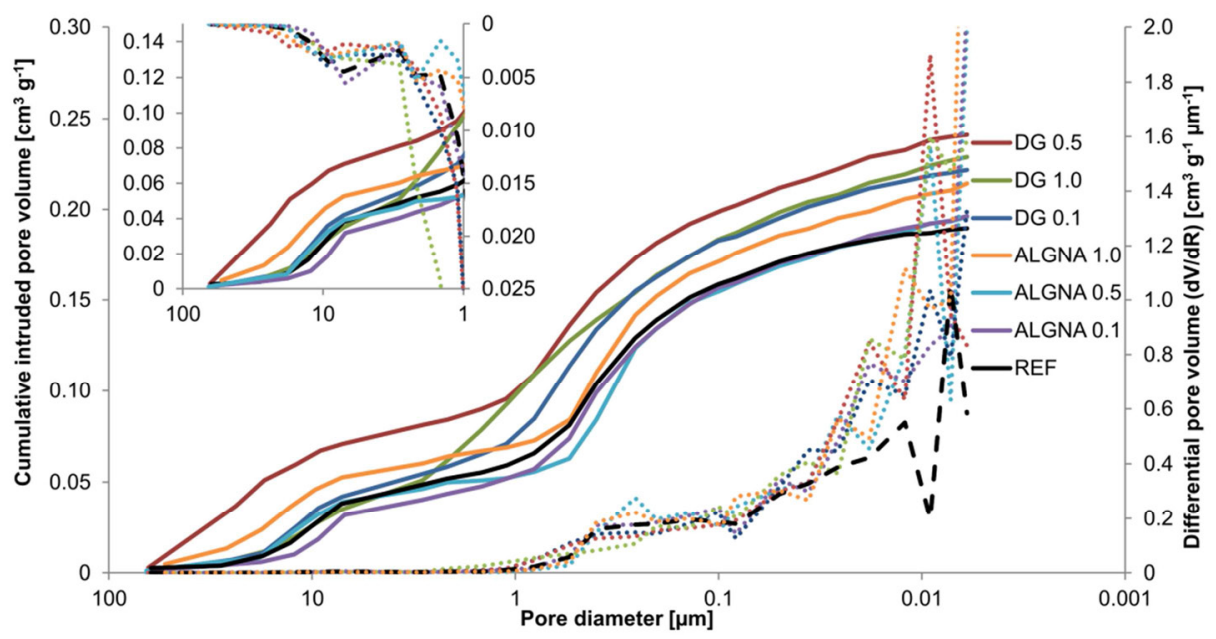

Fig. 2. Cumulative intruded pore volume and pore size distribution (dotted/dashed lines) of samples with DG and ALGNA. 
The total porosity (Fig. 3) is affected by the different volumes of large pores; however, it is mildly increased for all admixtures and doses, even the ones which reduce the volume of larger pores. The cause of the increase in the case of admixtures which do not help to develop large diameter pores can be seen in Fig. 1, where the slope of the cumulative pore volume curve is different for the reference mortar and the admixtured ones for the pores smaller than $0.1 \mu \mathrm{m}$. The shape of curves of all mortars with admixtures is within this interval different from the shape of curve of reference mortar meaning, that the admixtures gently promote the evolution of the small pores. This increase can be seen also on the charts from A. Izaguirre et al. in their works in the case of guar gum [12] and its hydroxypropyl derivative [1].

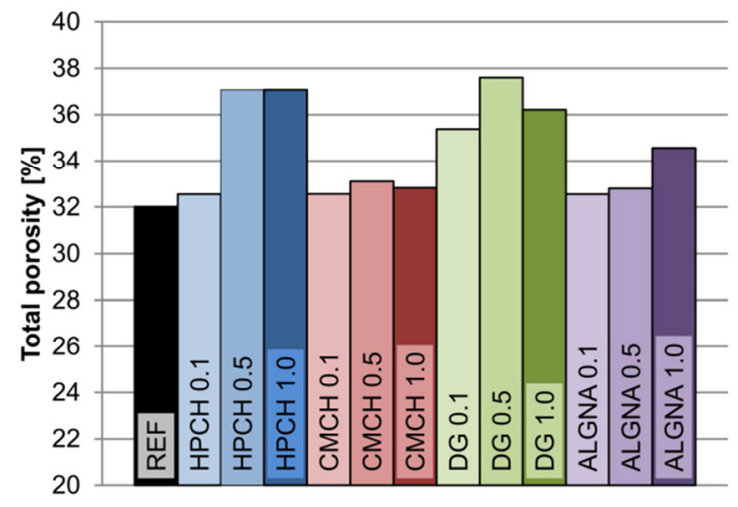

Fig. 3. Total porosity of tested samples.

\subsection{Water absorption coefficient due to a capillarity action}

Table 2. Capillary water absorption coefficient $(C)$ and apparent moisture diffusivity $\left(D_{w}\right)$ of tested samples

\begin{tabular}{|c|c|c|c|c|c|c|c|c|c|c|c|c|c|}
\hline & 产 & 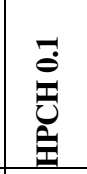 & 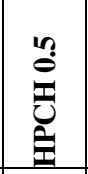 & 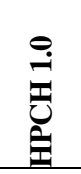 & 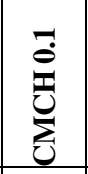 & 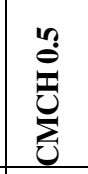 & 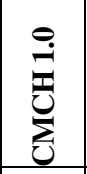 & $\begin{array}{l}\overrightarrow{0} \\
0 \\
0\end{array}$ & 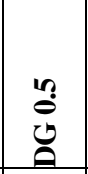 & & 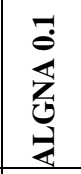 & 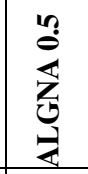 & 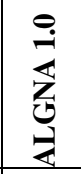 \\
\hline $\begin{array}{c}C \\
{\left[\mathrm{~kg} \mathrm{~m}^{-2} \mathrm{~s}^{-0.5}\right]}\end{array}$ & 0.214 & 0.182 & 0.162 & 0.154 & 0.197 & 0.226 & 0.226 & 0.266 & 0.366 & 0.254 & 0.232 & 0.216 & 0.142 \\
\hline $\begin{array}{c}D_{w} \\
{\left[\times 10^{-6} \mathrm{~m}^{2} \mathrm{~s}^{-1}\right]}\end{array}$ & 0.80 & 0.50 & 0.45 & 0.40 & 0.56 & 0.80 & 0.76 & 1.03 & 1.83 & 1.06 & 0.86 & 0.69 & 0.30 \\
\hline
\end{tabular}

The hygric properties of mortars described by capillary water coefficient and apparent moisture diffusivity are shown in Table 2. The capillary water coefficient, which is the gradient of the linear part of the absorption curve, is lower for the mortars with HPCH, lowest dose of $\mathrm{CMCH}$, and highest dose of ALGNA, meaning, that these admixtures in these doses hinder the moisture transport in the mortars, which results in their higher durability [1, 18]. The capillary water absorption coefficient reduction is caused by interruption of capillaries by air voids [18], thus mainly the mortars with high air content performed well. The exception is in the case of ALGNA 1, where air content in fresh mortar is not notably higher than in the reference mortar but, taking into account pore size distribution in Fig. 2, it contains higher volume of large pores in hardened state. The various behaviour of DG 0.5 and DG 1.0 mortars is probably also caused by their diverse pore size distribution. 


\subsection{Scanning electron microscopy}

On the most mortar samples studied by SEM, there are no signs of the biopolymers influencing the microstructure of the samples. As seen in Fig. 4a, the binder's microstructure in all cases consists of portlandite and calcite crystals with a capillary pores between them complemented by small amount of ettringite (rod-like crystals on the leftmost part of the Fig 4a) (ettringite is formed due to an impurities in kneading water and sand). Only in the case of DG addition (Fig. 4b), there is a noticeable change in the appearance of the binder phase caused by the web-like structures connecting the crystal clusters. These structures are found only in DG-modified mortars, and are therefore the direct consequence of the DG addition into lime material; they can be also responsible for the altered pore size distribution (Fig. 2) in DG 1.0 mortar.
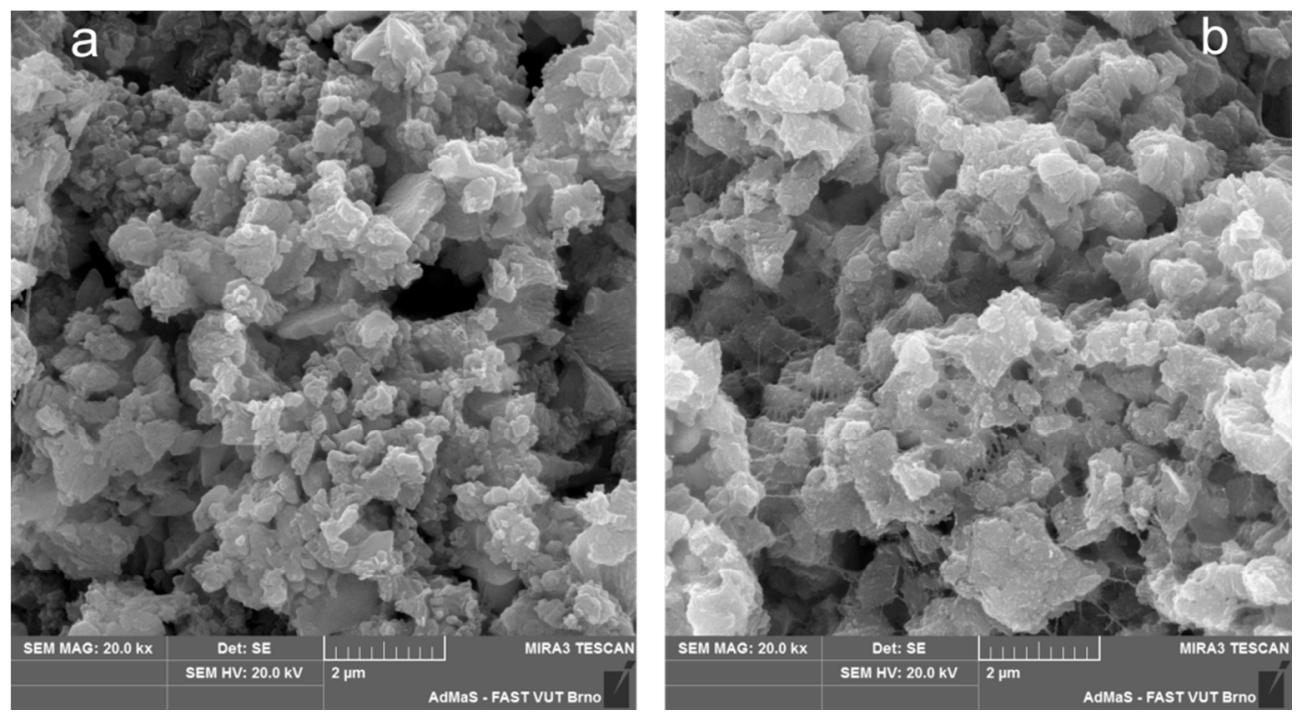

Fig. 4. SEM images of REF (a) and DG 1.0 (b) mortars.

\section{Conclusions}

The influence of four biopolymeric admixtures (hydroxypropyl- and carboxymethylchitosan, diutan gum, and sodium alginate) on the microstructure of aerial lime-based mortars with constant consistency was studied.

- Hydroxypropyl chitosan had, as the only one of the studied admixtures, air-entraining function. This promoted the occurrence of pores of diameter around $10 \mu \mathrm{m}$ and increase in total porosity. The air entraining function is beneficial for the reduction of capillary water coefficient, and thus improvement of durability.

- Carboxymethyl chitosan in the lowest dose of $0.1 \%$ also decreased the capillary water coefficient, but with no significant alteration of pore size distribution.

- Diutan gum, as the most water-demanding admixture, increased the total porosity of mortars, in the dose of $0.5 \%$ promoted evolution of large pores around $10 \mu \mathrm{m}$, and in the dose of $1.0 \%$ highly altered the pore size distribution of the mortars. Due to low air content in the mortars in combination with high total porosity, the samples showed the fastest moisture transport, impairing the durability. Diutan gum was the only admixture, addition of which led to modifications in the structure observable by scanning electron microscopy. 
- Sodium alginate in lower doses had no significant impact on porosity of mortar and the hygric properties remained similar to reference mortar; however, in the highest dose, the increase in volume of larger pores took place, and the moisture transport in the mortar was distinctly slowed.

The hydroxypropyl chitosan addition was found to be most useful for impairing the moisture transport, thus improving the durability of prepared mortars, but also the use of sodium alginate should be considered. The mixtures containing these two admixtures are to be subjected to durability tests to furtherly evaluate their impact on the properties of lime mortars. The carboxymethyl chitosan and diutan gum have showed none, or negative effect, respectively on the presumed durability of the materials and were not found beneficial for the mortars, at least in the studied doses.

The work has been financially supported by BUT specific research project. no. FAST-J-20-6289.

\section{References}

1. A. Izaguirre, J. Lanas, J.I. Álvarez, Cem. Concr. Res. 40, 1081-95 (2010)

2. L. J. Vicat, A Practical and Scientific Treatise on Calcareous Mortars and Cements, Artificial and Natural, Cambridge University Press, (Cambridge 2014)

3. J. Lanas, J. I. Álvarez, Cem. Concr. Res. 33, 1867-86 (2003)

4. J. S. Pozo-Antonio, Contr. Build. Mater. 77, 472-8 (2015)

5. A. Arizzi, J. Martínez-Martínez, G. Cultrone, D. Benavente, Key Eng. Mater. 465, 483-6 (2011)

6. A. R. Santos, M. do Rosário Veiga, A. S. Silva, J. de Brito, J. I. Álvarez, Constr. Build. Mater. 187, 907-22 (2018)

7. M. Arandigoyen, J. L. Pérez Bernal, M. A. Bello López, J. I. Álvarez, Appl. Surf. Sci. 252, 1449-59 (2005)

8. I. Papayianni, M. Stefanidou, Constr. Build. Mater. 20, 700-5 (2006)

9. R.M.H. Lawrence, P. Walker, Structural Analysis of Historic Construction: Preserving Safety and Significance. 885-9 (London 2008)

10. F. Van Der Vurst, S. Grünewald, D. Feyes, K. Lesage, L. Vandewalle, J. Vantomme, G. De Shutter, Cem. Concr. Compos. 82, 190-201 (2017)

11. J. Plank, Appl. Microbiol. Biotechnol. 66, 1-9 (2004)

12. A. Izaguirre, J. Lanas, J. I. Álvarez, Cem. Concr. Compos. 33, 309-18 (2011)

13. M. Vyšvařil, M. Hegrová, T. Žižlavský, Solid State Phenom. 276, 69-74 (2018)

14. T. Žižlavský, M. Vyšvařil, P. Bayer, P. Rovnaníková, Solid State Phenom. 276, 75-82 (2018)

15. T. Žižlavský, M. Vyšvařil, P. Bayer, P. Rovnaníková, $5^{\text {th }}$ Historic Mortars Conference 1279-91 (Paris 2019)

16. M. Lasheras-Zubiate, I. Navarro-Blasco, J. I: Álvarez, J. M: Fernández, J. Haz. Mater. 194, 223-231 (2011)

17. T. Žižlavský, M. Vyšvařil, P Rovnaníková, IOP Conf. Series: Mat. Sci. \& Eng. 379, 012006 (2018)

18. H. Paiva, L. P. Esteves, P.B: Cachim, V. M. Ferreira., Constr. Build. Mater. 23, 1141-6 (2009) 